\title{
A Contrastive Study on Metadiscourse Elements Used in Humanities vs. Non Humanities across Persian and English
}

\author{
Gholam Reza Zarei \\ English Language Center,Isfahan University of Technology \\ Isfahan, 84156-83111, Iran. \\ Tel: 98-311-3912843, Fax: 98-311-3912836 \\ E-mail:grzarei@cc.iut.ac.ir \\ Sara Mansoori \\ Department of Teaching English,Islamic Najafabad Azad University \\ Najaf abad, Isfahan, Iran. \\ E-mail:s-mansoori@iaun.ac.ir
}

\begin{abstract}
The present study studied contrastively the use of metadiscourse in two disciplines (applied linguistics vs. computer engineering) across two languages (Persian and English). The selected corpus was analyzed through the model suggested by Hyland and Tse (2004). The results revealed the metadiscursive resources are used differently both within and between the two languages. As for the two courses, applied linguistics representing humanities relied heavily on interactive elements rather than interactional ones, compared with computer engineering representing non humanities. The analysis attests that humanities focus on the textuality at the expense of reader involvement. As indicated by the result, the idea of disciplinary prominence of metadiscourse across different languages needs to be cautiously taken into account.
\end{abstract}

Keywords: Academic text, Metadiscourse, English language, Persian Language, Computer Engineering, Applied Linguistics

\section{Introduction}

Discourse conventions have been shown to characterize different genres, among which Research Articles have recently come under lots of investigations. Through these discursive means scientists can acquire concepts, norms, values and ideological underpinning of a particular discipline. In fact, scientists of different fields access not only the subject matter but also a specialized form of literacy through research articles. That is, they can acquire rhetorical and linguistic practices of a particular community, rendering them distinct from one another (Ballard \& Clanchy, 1991). One important discourse feature which characterizes academic communities is 'metadiscourse', through which writers of academic disciplines intrude into the texts and represent themselves and their readers in one way or another.

Generally, academic communication distinguishes two types of knowledge: the external world knowledge, usually put as propositional meaning, and the internal world knowledge construed as non-propositional meaning or metadiscourse (Vande Kopple, 1985). Crismore, Markhanen, and Steffenson (1993) contend that the linguistic material not contributing to the ideational or propositional content is taken as metadiscourse since it assists the reader in organizing, interpreting, and evaluating the given information.

Despite the categorical distinctions made, Hyland and Tse (2004) contend that the two types of meaning are not readily identifiable. It is very difficult to maintain the distinction between the two levels of meaning as it is claimed that meaning as such is the re-synthesis of various elements functioning together. That is, if 'meaning' results from the integration of different ideational, contextual, textual, and interpersonal elements, for stronger reasons it sounds illogical to speak of separate layers of meaning-metadiscourse as sharply distinct from ideational meaning. Similarly, Crismore and Farnswarth (1990), while ignoring the idea of non-propositional meaning as metadiscourse, incorporate into their classifications referential, and informational metadiscourse, implying that the two sides of meaning can be represented under one umbrella term to emphasize the integrative nature of meaning. Therefore it will be of no surprise if we find a piece of discourse serving both functions. This argument in line with Hyland (1998a) is supposed to rule out the possibility of relegating metadiscourse to a secondary position, but to take it as an obligatory process of communicating meaning. 
Though the consensus is hardly to be achieved over the status of metadiscourse, it is generally conceded that metadiscourse plays a key role in organizing discourse and also in engaging the audience, extending the importance of meaning beyond the ideational to interpersonal and textual functions. Metadiscourse is an interactive and rhetorical character of academic writing, which establishes social and communicative engagement between writer and reader focusing on "those aspects of the texts which explicitly refer to the discourse or the writer's stance towards either its content or the reader" (Hyland, 1998a: 438). In other words, academic writers generate texts as much to represent some external reality as to display their attitudinal positions in relation to the external reality and the recipients thereof. As a matter of fact, the external reality is created and realized on some internal ordered map represented via certain stylistic devices called metadiscourse.

Metadiscourse thus refers to the interaction between writer and reader in academic texts. And, it is utilized to manage the role the writer adopts in relation to the content and reader, which is respectively viewed as textual indicating how carefully a text is encoded to achieve coherence and organization, and as interpersonal used to help writers express their attitudinal and personal reactions towards the readers (Halliday, 1994). Of the two aspects, interpersonal function is believed to be a predominantly encompassing feature which also subsumes textual function as well. Hyland (2004) argues that textual function does not make a very clear and independent category, but it creates the conditions for both propositional and interpersonal aspects to materialize the sequential integrity of the text. Therefore, this view finds metadiscourse not so much of textual nature as of interpersonal function. As Hyland (ibid) says, "metadiscourse is interpersonal in that it takes account of the reader's knowledge, textual experiences, and processing needs and that it provides writers with an armory of rhetorical appeals to achieve this"(p.161).

Though its macro-function is primarily interpersonal, it is accepted that metadiscourse is variable across scientific communities and disciplines. For instance, while some scientific communities may leave much of the message to be decided by the reader some others may go to great lengths providing a reader-friendly context. Such distinctive characteristics of genre can prompt writers to capitalize on varying degrees of metadiscourse in regard to their addressees, leading to what has been called as writer responsible versus reader responsible stances (Crismore, and Farnswarth, 1990; Hyland and Tse, 2004). Such variation embodies different social relationships between the reader and the writer as well as different values and beliefs underlying discursive practices in various discourse communities.

Recently, an interest has been growing in the genre-based characterization of metadiscourse. Mauranen (1993) thinks that such a growing significance originates in the inherent paradox involved in metadiscourse, and claims that scientific texts are at the same time culturally independent and culturally variable, signifying the specificity of genre and distinctiveness of rhetoric or scientific community cultures. In the same line of thinking, Hyland (1998a) stresses the independence of metadiscourse as intimately linked to the norms and standards of special cultural and professional communities. Moreover, metadiscourse is considered as a critical feature of good native and learner language writing (Intraprawat and Steffenson, 1995), whereby writers for international scientific journals can also achieve intelligibility of communication through proper discipline norms, values and assumptions to trail their path to academic promotions. Thus the present study seeks to study the important, yet neglected aspect of the disciplines in Persian and English academic articles, and also attempt is made to compare and contrast disciplines in the two languages. This is to specify the rhetorical preferences that characterize the Persian and English scientific communities, with the hope that the findings can be pedagogically utilized and improve the international communication.

\section{Metadiscourse Investigations}

Investigations into the written academic genres have demonstrated that different languages and disciplines make specific use of writing norms to make themselves realized. It has been shown that to be admitted as an insider within a community requires gaining sight into the particular discourse of each community. In this line of inquiry, metadiscourse in academic genre has received significant attention as an important rhetorical aspect which could affect the communicative ability of those concerned. Metadiscourse has been studied in various contexts and texts, e.g., casual conversation (Schiffrin, 1980); school textbooks (Crismore, 1989); science popularization (Crismore \& Farnsworth, 1990); post-graduate dissertation (Bunton, 1999); Darwin's Origins of the Species (Crismore \& Farnsworth, 1989); company annual reports (Hyland, 1998b); introductory course books (Hyland, 1999); undergraduate textbooks (Hyland, 2000); slogans and headlines (Fuertes-Olivera et al., 2001); and metadiscourse in academic writing: a reappraisal (Hyland and Tse, 2004).

Due to the peculiarity of the metadiscursive elements, some of the studies have investigated it in different disciplines and languages, e.g., Finish-English economic texts (Mauranan, 1993), Spanish-English economic texts (Valero, 1996), a comparison of linguistics and medicine abstracts (Melander et al., 1997) and medicine, economics and 
linguistics in English, French and Norwegian (Breivega et al, 2002). Few of these studies on metadiscourse in different disciplines and languages are reviewed below:

As a case in point, Hyland (1999) investigated the use of metadiscourse in two corpora-textbooks and research articles in three disciplines-Biology, Applied Linguistics and Marketing. The results demonstrated that the applied linguistics texts comprised considerably more evidentials and relational markers; the biology authors favored hedges; and marketing textbooks had fewer evidentials and endophorics. Hyland showed that biology had the greatest variation in most categories of metadiscourse both across genres and disciplines. It was also indicated that marketing and applied linguistics texts were more consistent across genres and both contained large differences in hedges and connectives. There were also found significant genre discrepancies in the use of evidentials and person markers in marketing, and endophorics and relation markers in applied linguistics. In general, there were greater genre differences than disciplinary ones, and the textbooks had a propensity to show evidences of greater disciplinary diversity than the research articles.

Likewise, Dahl (2004) investigated two kinds of metadiscourse (locational and rhetorical metatext) in three disciplines (Linguistics, Economics and Medicine) across three languages (English, Norwegian and French). She stated that 'economics displayed a somewhat higher frequency of the two types than did Linguistics for both English and Norwegian, while for French there was hardly any difference within these two disciplines; for all three languages medicine used far less metatext than the other two disciplines.' (p., 1818). Also, medicine made the least use of metatext and its texts were presented in a highly structured format: Introduction-Methodology-Results-Discussion (Swales, 1990). She concluded that economics and linguistics in English and Norwegian showed very similar patterns, using much more metatext than French; within medicine, all three languages displayed a uniform pattern of little metatext.

The use of metadiscourse in academic articles written in English by English and Norwegian native speakers across three disciplines (Sociology, Psychology and Philosophy) has also been studied by Blagojevic (2004). Regardless of the languages, Blagojevic noticed that Psychology writers were reluctant to use the plain ways to state or remind the readers of the parts of the material which followed or preceded. They also used less attitude markers, but philosophy writers made most of the direct comments. Blagojevic's study also showed that philosophy writers had a high degree of diversity in their writing, while psychology writers had the highest degree of standardization in writing and sociology writers were somewhere in between.

Hyland and Tse (2004) carried out a research on the use of metadiscourse in postgraduate dissertations in six disciplines: Applied linguistics, Public administration, Business Studies, Computer science, Electric engineering, and Biology. The results showed that the humanities and social science disciplines employed more metadiscourse than the non-humanities. The study showed the greater use of metadiscourse in the humanities and more inter-disciplinary balance of interactive metadiscourse but its higher proportion in the science dissertations. Also, the results indicated that boosters and engagement markers were almost equally distributed across disciplines, but hedges were over twice more common in the humanities and self-mentions almost four times more frequent. Transitions were more carefully used in the humanities, but emphatics were used more in the non-humanities especially in engineering. Although the use of evidentials, which provides support for the writers' positions, was a characteristic of the humanities, they were most used in biology to show the importance of relating the current research to the preceding work of other authors in this field.

In another study, Zarei and Mansoori (2007) investigated the metdiscursive patterns across Persian and English languages in computer engineering and applied linguistics and found out that both English and Persian languages emphasized text coherence over interpersonal functions of language. Also, the results revealed that Persian involved more presuppositions in the text, with a great portion of meaning left to be decided by the reader.

Although a general picture of the metadiscourse has been presented in the previous studies, due to the rhetorical importance and also dynamic character of 'metadiscourse' in different disciplines and languages, it seems necessary to scrutinize the issue further. Moreover, since available studies seem to be scanty dealing with the subject in Persian disciplines compared with their English counterparts, the present study is thus intended to investigate the distribution of metadiscourse in two different disciplines, namely, Computer Engineering and Applied Linguistics.

\section{Research Purpose}

The present study set out to study metadiscourse in research articles to capture the discipline and language specific nature of metadiscoursive elements. In line with previous studies, especially the one conducted by the present authors, the study focuses on two disciplines and two languages with the hope that the diversified results from different disciplines will get more consolidated as regards language contrastive analyses. 


\section{Corpus}

As mentioned above, our corpus involved two disciplines (Applied Linguistics and Computer Engineering) and two languages (English and Persian). The study decided on the comparison of English language as an international lingua franca and Persian as it is most probable that Iranians are subject to their first language interference, which may lead to the breakdown or misinterpretation of communication.

The disciplines, Applied Linguistics and Computer Engineering, were selected to represent two general streams of disciplines, namely, humanities and non-humanities, respectively. These two widely apart fields were supposed to represent the distinct trends of academic studies so that the results could be generalized across the two languages, though on a broad level.

The articles were selected from well-known, refereed and recently published journals (2004, 2005 \& 2006). In order to investigate different writings, hence balancing out the problem of idiosyncrasy and particularity of writers' styles, the articles were chosen randomly. Articles whose authors were a native speaker of English and Persian were selected for our study. Moreover, at least one author was a native speaker or one of the members of academic staff in U.S or U.K for English articles and a native speaker of Persian for the Persian research articles. A great effort was made to select the articles as diverse in subjects as possible to be able to increase the external validity of the results.

The number of the selected articles from the two disciplines and languages is presented in the following table:

\section{Table 1}

\section{Data Analysis}

The model used for the analysis of metadiscourse was the one suggested by Hyland and Tse (2004). This model was used for the purpose since it is designed to specifically capture the underlying principles of academic writing. To this end, Hyland and Tse (2004) claim that metadiscourse needs to be conceptualized as an interpersonal feature of communication, which stands in sharp contrast to Crismore's (1989), and Williams' (1999) views that metadiscourse contributes towards either propositional or interpersonal functions. Furthermore, unlike Mauranen (1993) and Bunton (1999) who see metatext as the writer's self-awareness of text, Hyland and Tse (ibid) believe that 'metadiscourse represents the writer's awareness of the unfolding text as discourse: how writers situate their language use to include a text, a writer and a reader' (p. 167). The intended model, which is presented below, is specifically named 'a model of metadiscourse in academic texts'.

\section{Table 2}

\section{Results and Discussions}

\subsection{Overall Investigation}

The quantitative analysis points to the importance of metadiscoursal elements across the two disciplines and the two languages. The total metadiscursive elements count show 6257 instances out of 102293 words produced. This translates to about one instance per every sixteen words. As to the two languages, English displayed a slightly lower number in comparison with Persian (2811 out of 50602 vs. 3446 instances out of 51691, respectively).

Further analysis of the two disciplines revealed that there was one metadiscourse element almost per fourteen words in Applied Linguistics corpus and one per eighteen words in Computer engineering corpus within the two languages. These quantitative results confirm that academic texts are made up of a relatively large number of metadiscourse elements, which can clearly be conducive to the quality, intelligibility and communication in the academic contexts. Interestingly, the results reject the idea that metadiscourse is just marginal to the texts (Crismore and Farnsworth, 1990). Below, first distinct disciplines in each language and then the two identical disciplines (representing general streams of humanities vs. non humanities) across the two languages are compared and contrasted.

\subsection{English Disciplines Compared}

The results in this part show that there is one metadiscourse element almost per 15 words in the English Applied Linguistics, but almost per 20 words in the English Computer engineering corpus. In English corpus, as Table 3 shows, Applied Linguistics uses both interactive and interactional resources more than Computer engineering ( $4.33 \%$ vs. $3.41 \%$ and $2.21 \%$ vs. $1.4 \%$, respectively). Note that the percentages hereafter presented are all based on the total number of metadiscourse items identified in relation to the total number of words used in each corpus. The statistical analyses revealed that these differences were significant. The findings show the greater guidance and involvement of the readers in the text with which Applied Linguistics as a volunteer of the humanities is concerned. The analysis of the subcategories of the metadiscoursal resources as shown in Table 3 reveals that the two disciplines differ in the way they prioritize the respective elements in the English corpus. Both Applied Linguistics and Computer engineering capitalize maximally on the 'transitions $(1.25 \%$ vs $0.85 \%)$ and minimally on the 'attitude 
markers $(0.08 \%$ vs $0.06 \%)$ respectively. As a general rule, it seems that both disciplines find 'transitions' central to academic writing, but as statistical analysis shows Applied Linguistics attempts significantly more to ensure that readers can recover their intentions ( $\mathrm{z}$ test $=4.41)$. It is interesting indeed to notice that English academic writers in both corpora (Applied Linguistics and Computer engineering) do not differ in making use of attitude markers by making the least use of them, which may suggest that both English disciplines require the highest degree of detachment and objectivity. English Applied Linguistics assumes the second place for 'evidentials', whereas Computer engineering relegates it down to the sixth position, indicating that Applied Linguistics provides a stronger ground for the documentation of the information, possibly because they have to deal with less quantitative data. Regarding 'code glosses' and 'hedges', the two disciplines have taken up conservative positions, with both using nearly the same number, and increasing the two proportionally equally. Since code glosses are supposed to provide interpretation for the findings, the writers have taken cautionary measures so as not to sound biased, by making use of almost the same number of hedges to soften the force of their interpretation. Self-mentions' greater use in Applied Linguistics corpus shows more presence of writers, implying that humanities in English uphold a stronger voice in their communications than the English non-humanities. Another interesting point is that English Applied Linguistics uses boosters more than the Computer Engineering, but at the same time relies on the greater use of hedges, implying that humanities exercise more caution in commenting on the findings.

On the whole, except for 'Engagement' and 'Attitude Markers' all other subcategories are statistically distinct in the two disciplines. This may prove that fact that the two disciplines are metadiscourse-conscious. Of course one needs to remember the limits of the corpus used here to make sound interpretations.

Table 3

\subsection{Persian Disciplines Compared}

In Persian corpus, as Table 4 shows, Applied Linguistics uses both interactive and interactional resources more than Computer engineering, exactly similar to the English disciplines compared above $(5.23 \%$ vs $4.82 \%$ and $1.72 \%$ vs $1.07 \%$, respectively). Persian Applied Linguistics also uses evidentials more than the Computer engineering like English Applied Linguistics. An important point is that unlike English corpus Persian Applied Linguistics and Computer Engineering have both made use of boosters more than hedges. This can support the idea that Persian writers of academic texts are inclined to designate more certainty of the results even in the Applied Linguistics as a volunteer of the humanities where results are generally more cautiously interpreted. Also, Persian corpus makes more differentiation between the two disciplines by making more use of Attitude markers $(0.18 \%$ vs $0.09 \%$; applied linguistics vs. computer engineering respectively) and engagement markers ( $0.04 \%$ vs $0.01 \%$; applied linguistics vs. computer engineering respectively). Although attitude markers and self-mentions are not assigned exactly the same status, they both appear in the last two positions for the two Persian disciplines, slightly revealing that interpersonal elements may not be of high significance in Persian.

The differentiation between the two disciplines in making use of metadiscourse elements is obscured as four metadiscourse elements including transitions, code glosses, frame markers and self-mentions do not show significant differences (See Table 4). However, this does not rule out the specificity of metadiscourse across the two disciplines in Persian (Total $\mathrm{z}=6.3$ ).

Table 4

\subsection{English and Persian Non-Humanities Compared}

Computer Engineering texts representing non-humanities were carefully analyzed to unravel the nature of disciplinary distinctions in the two different languages. As Table 5 shows, Persian Computer engineering uses interactive resources more than English computer engineering (4.82\% vs 3.41\%), but English computer engineering uses interactional elements more than Persian Computer engineering (1.4\% vs $1.07 \%)$. This shows that for Persian comprehensibility of text overrides the relationship that is to be established between the writer and reader. In the same vein, Persian writers' greater use of 'transitions' further supports that the coherence of text is essentially important. Moreover, Engagement markers are also more frequent in English non-humanities, one more time showing the English writers' special attention to the relationship they need to make with the readers.

Also, 'code glosses' appearing in the second position in Persian computer engineering and fifth in English, indicates that Persian writers offer more interpretations of the results. To substantiate their positions, Persian writers provide more 'boosters', that is, they speak out directly about their views, while English writers make their text more documented, and more cautious by making greater use of 'evidentials' and 'hedges'. Though the two disciplines made no specific use of 'frame', 'endophoric', 'attitude markers' and 'self-mentions'(See Table 5), the overall 
analysis shows that the non-humanities are distinct in both interactive and interactional components of metadiscourse in the two languages.

Table 5

\subsection{English and Persian Humanities Compared}

Applied Linguistics as representative of humanities across the two languages was studied and revealed a more diverse pattern across the two languages, compared to the non humanities. As shown in Table 6, there are meaningful differences between all of the metadiscourse elements except for endophoric markers. The trend for humanities is exactly similar to the non-humanities with both English and Persian Applied Linguistics using interactive resources more than the interactional ones. The only difference is that the gap in here is wider. The two languages differ in the way they prioritize the respective elements. English humanities capitalizes maximally on the 'transitions (1.25\%) and minimally on the 'attitude markers $(0.08 \%)$. Persian also uses 'transitions' $(1.70 \%)$ as the first priority, which is also more frequent than its English counterpart, but unlike English it uses 'engagement markers' $(0.04 \%)$ as the last one. It is interesting indeed to notice that English humanities writers make the least use of 'attitude markers', leaving the responsibility to the reader to make possible interpretation. English uses evidentials, hedges, and engagement markers more while Persian uses transitions, code glosses, boosters more. Generally, this finding shows the documentation, caution, and the relations of writers and readers as worthwhile on the part of the English academic writers, and the significances of cohesion, text understandability and writers' resolute expression of ideas on the part of the Persian academic writers. Unlike the non-humanities corpus which made no language specific-use of self-mentions, great importance is given to this element in the English Applied linguistics corpus which shows significance of the presence of author in humanities in comparison with both English non-humanities and Persian humanities. Again the overall result is indicative of the specificity of metadiscourse in the humanities across the two languages (Total $\mathrm{z}=3.9$ ).

Table 6

\section{Conclusion}

The results of this study are suggestive of discipline and community based distinct conventions. As regards the languages concerned, the selected Persian articles outweighed their English counterparts, by capitalizing more on metdiscourse elements. As representative of humanities, applied linguistics outweighed computer engineering in the use of metadiscursive resources. Our findings lend support to the idea that languages and disciplines rely on specific use of metadiscourse, making themselves understandable to their readership differently.

As to the languages studied here, Persian proved to value textuality more, relying less on the establishment of relationship with the readers, while English showed comparatively lower reliance on the metadiscursive resources, yet showing the interactional side of the metadiscourse slightly more. Disciplines also proved to be different, with humanities showing greater reliance on metadiscourse. This finding may be attributed to the fact that humanities do not work on the quantitative data, thereby they need to get established through further compensatory measures such as using more textual, transitional, and interactional elements.

The discipline specificity can uncover the fact that academic articles demonstrate independent disciplinary visions, i.e., they develop some dynamic rhetorical forms relative to the situations serving to stabilize their experiences and also to the convictions and expectations of discoursal communities seeking to achieve certain academic goals of mutual intelligibility. In other words, the academic writers of different disciplines may be largely subjected to distinct modes of interaction leading to the conceptualization and construction of distinct worlds which are embedded in a particular culture of a particular discoursal community.

In reference to the distinctiveness of languages it needs to be stated that languages utilize certain linguistic forms and conventions which are encoded by the socio-cultural system of communication (Halliday, 1994). That is, all language use is a social and communicative act in which mutual cooperation and assistance are socio-culturally determined and provided between the producer and receiver of the language to exchange information. And it is through the lenses of the socio-rhetorical framework that some languages produce writer-based prose and some others prefer reader-oriented one (Blagojevic, 2004). In this vein, metadiscourse is not an autonomous stylistic feature of language dissociated from the broader social texture of the two languages, which can be used, reused or left unused at will by the writers. But it is an essential device which can be created out of the societal requirements, which are superordinately determined by the cultural norms of a given language, and subordinately linked to the expectations of a particular professional community. The results go contrary to the idea of the universal scientific discourse propounded by Widdowson (1979). Thus, as a case in point, Persian writers of academic articles addressing English readers, in particular native readers, may need to tone down their overuse of interactive and scale up their underuse of interactional metadiscourse elements in order to arrive at a balanced view of communication 
based on the target native standards. Therefore, effective writing in different cultures involves a different culture-oriented deployment of resources to represent text and reader (Hyland (2004).

\section{References}

Ballard B. \& J. Clanchy (1991). Assessment by misconception: cultural influences and intellectual traditions in L. Hamp-Lyons (eds), Assessing Second Language Writing in Academic Contexts (pp. 19-35). Norwood, NJ: Ablex Pp. 19-35.

Blagojevic S. (2004). Metadiscourse in academic prose: A contrastive study of academic articles written in English by English and Norwegian speakers. Studies about Linguistics 5: 1-7.

Breivega K., D. Dahl \& K. Flottum (2002). Traces of self and others in research articles. A comparative pilot study of English, French and Norwegian research articles in medicine, economics and linguistics' International Journal of Applied Linguistics 12(2): 218-239.

Bunton D. (1999). The use of higher level metatext in PhD theses. English for Specific Purposes, 18: 41-56.

Crismore A. (1989). Talking with Readers: Metadiscourse as Rhetorical Act. New York: Peter Lang.

Crismore A. \& R. Farnsworth (1989). Mr. Darwin and his readers: Exploring interpersonal metadiscourse as a dimension of ethos. Rhetoric Review 8 (1): 91-112.

Crismore A. \& R. Farnsworth (1990). Metadiscourse in popular and professional science discourse in Nash, W. (eds), The writing scholar: Studies in academic discourse Sage, Newbury Park/London. Pp. 118-136.

Crismore A., R. Markkanen \& M. Steffensen (1993). Metadiscourse in persuasive writing: A study of texts written by American and Finnish university students. Written Communication 10 (1): 39-71.

Dahl T. (2004). 'extual metadiscourse in research articles: A marker of national culture or of academic discipline? Journal of Pragmatics 36: 1807-1825.

Fuertes-Olivera PA, M. Velasco-Sacristan, A. Arribas-Btio \& E. Samaniego-Ferntidez (2001). Persuasion and advertising English: Metadiscourse in slogans and headlines. Journal of Pragmatics 33: 1291-1307.

Halliday, M. A. K. (1994). An Introduction to Functional Grammar ( $2^{\text {nd }}$ ed) London: Edward Arnold.

Hyland, K. (1998a). Persuasion and context: The pragmatics of academic metadiscourse. Journal of Pragmatics 30: 437-455.

Hyland, K. (1998b). Exploring corporate rhetoric. Metadiscourse in the CEO's letter. Journal of Business Communication 35(2): 224-245.

Hyland, K. (1999). Talking to students: Metadiscourse in introductory coursebooks. English for Specific Purposes 18(1): 3-26.

Hyland, K. (2000). Disciplinary Discourses: Social Interaction in Academic Writing. London: Pearson.

Hyland, K. (2004). Disciplinary interactions: Metadiscourse in L2 postgraduate writing. Journal of Second Language Writing 13: 133-151.

Hyland, K. \& P. Tse (2004). Metadiscourse in academic writing: a reappraisal. Applied Linguistics 25 (2): 156-177.

Intraprawat, P. \& M. Steffensen (1995). The use of metadiscourse in good and poor ESL essays. Journal of Second Language Writing, 4(3): 253-72.

Mauranen, A. (1993). Contrastive ESP rhetoric: Metatext in Finnish-English economics texts. English for Specific Purposes, 12, 3-22

Melander, B., J. Swales \& K. Fredrickson (1997). Journal abstracts from three academic fields in the United States and Sweden: national or disciplinary proclivities? in Duszak A. (eds.), Culture and styles of academic discourse Berlin/ New York: Mounton de Gruyter. Pp. 251-272.

Schiffrin, D. (1980). Metatalk: Organizational and evaluative brackets in discourse. Sociological Inquiry 50: 199-236.

Swales, J. (1990). Genre analysis. English in academic and research settings. Cambridge: Cambridge University Press.

Valero-Garces, C. (1996). Contrastive ESP rhetoric: Metatext in Spanish-English economics texts. English for Specific Purposes 15( 4): 279-294.

Vande Kopple, W. J. (1985). Discourse about discourse. College Composition and Communication 36: 82-93. 
Widdowson, H. G. (1979). The description in scientific language in H. G. Widdowson (eds), Explorations in Applied linguistics. Oxford: Oxford University Press. Pp.57-61.

Williams, I. A. (1999). Results sections of medical research articles: analysis of rhetorical categories for pedagogical purposes. English for Specific Purposes 18: 347-366.

Zarei, G. R. \& S. Mansoori (2007). Metadiscourse in academic prose: A contrastive analysis of English and Persian research articles. The Asian ESP Journal, vol.3(2), 24-40.

Table 1.The Corpus used in this research

\begin{tabular}{|c|c|c|c|c|}
\hline Language & Disciplines & No. of articles & Word count & The total word count \\
\hline \multirow{3}{*}{ English } & Applied Linguistics & 4 & 25071 & \multirow{2}{*}{50602} \\
\cline { 2 - 4 } & Computer Engineering & 5 & 25531 & \\
\hline \multirow{3}{*}{ Persian } & Applied Linguistics & 5 & 25510 & \multirow{2}{*}{51691} \\
\cline { 2 - 4 } Total & Computer Engineering & 5 & 26181 & 102293 \\
\hline
\end{tabular}

Table 2. Hyland and Tse (2004) taxonomy of metadiscourse

\begin{tabular}{|c|}
\hline $\begin{array}{l}\text { 1) Interactive Resources: They help to guide reader through the text: } \\
\text { a) Transitions (T): They express semantic relation between main clauses. Examples: in addition, } \\
\text { thus, but, and } \\
\text { b) Frame Markers (Fm): They refer to discourse acts, sequences, or text stages. Examples: finally, } \\
\text { to conclude, my purpose here is to } \\
\text { c) Endophoric Markers }(\text { En): They refer to information in other parts of the text. Examples: noted } \\
\text { above, see figure, in section } \\
\text { d) Evidential Markers }(\boldsymbol{E v}) \text { : They refer to sources of information from other texts. Examples: } \\
\text { according to X/(Y, } 1990) / Z \text { states } \\
\text { e) Code glosses (Co): They help readers grasp functions of ideational material. Examples: namely, } \\
\text { e.g., such as, in other words }\end{array}$ \\
\hline 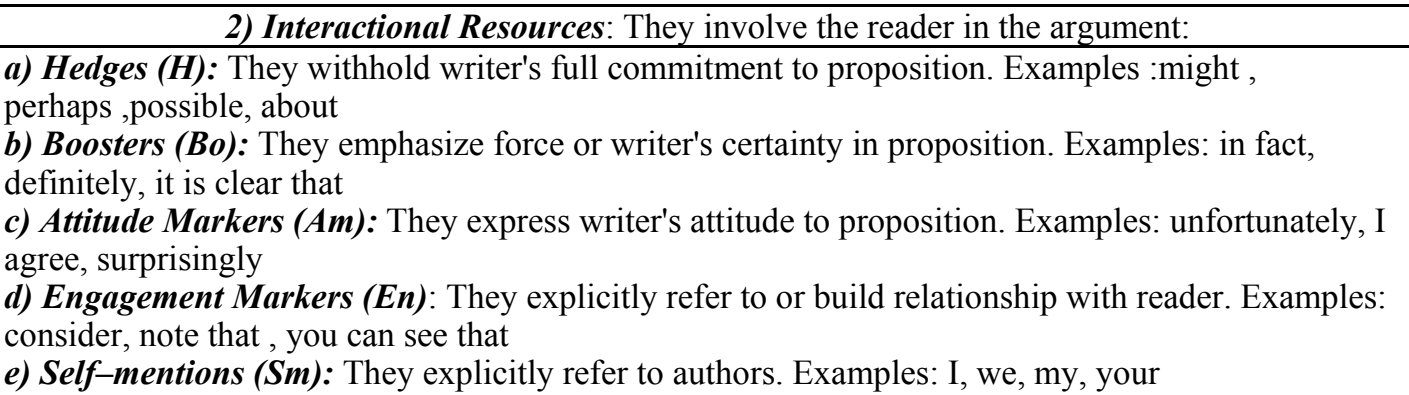 \\
\hline
\end{tabular}

Note: The shortened forms of categories enclosed in parentheses will appear in the analysis

Table 3.The use of metadiscourse element in English corpus

\begin{tabular}{|c|c|c|c|c|c|c|c|c|c|c|c|c|c|}
\hline & \multicolumn{12}{|c|}{ Metadiscourse } \\
\hline & & \multicolumn{6}{|c|}{ Interactive } & \multicolumn{6}{|c|}{ Interactional } \\
\hline English & $\begin{array}{c}\text { No. } \\
\text { of } \\
\text { words }\end{array}$ & T\% & Fm\% & En\% & Ev\% & $\begin{array}{c}\text { Co } \\
\%\end{array}$ & $\begin{array}{c}\text { Total } \\
\%\end{array}$ & $\mathrm{H} \%$ & $\begin{array}{l}\text { Bo } \\
\%\end{array}$ & $\begin{array}{c}\mathrm{Am} \\
\%\end{array}$ & $\begin{array}{c}\text { Eng } \\
\%\end{array}$ & $\begin{array}{c}\mathrm{Sm} \\
\%\end{array}$ & $\begin{array}{l}\text { Tot } \\
\text { al\% }\end{array}$ \\
\hline $\begin{array}{l}\text { Computer } \\
\text { engineering }\end{array}$ & 25531 & 0.85 & 0.81 & 0.73 & 0.5 & 0.5 & 3.41 & 0.56 & 0.19 & 0.06 & 0.2 & 0.39 & 1.4 \\
\hline $\begin{array}{c}\text { Applied } \\
\text { linguistics }\end{array}$ & 25071 & 1.25 & 0.4 & 0.38 & 1.21 & 1 & 4.33 & 0.96 & 0.42 & 0.08 & 0.13 & 0.62 & 2.21 \\
\hline Total & 50602 & 2.1 & 1.3 & 1.11 & 1.71 & 1.5 & 7.74 & 1.52 & 0.61 & 0.14 & 0.33 & 1.01 & 3.61 \\
\hline z-test result & $* * * * *$ & $\begin{array}{c}4.41 \\
*\end{array}$ & $4.47^{*}$ & $5.29 *$ & $\begin{array}{c}8.69 \\
*\end{array}$ & $\begin{array}{c}6.22 \\
*\end{array}$ & 5.36* & $\begin{array}{c}16.9 \\
*\end{array}$ & $\begin{array}{c}15.0 \\
*\end{array}$ & 0.85 & 1.93 & $\begin{array}{c}3.65 \\
*\end{array}$ & $\begin{array}{c}\mathbf{6 . 8 4} \\
*\end{array}$ \\
\hline
\end{tabular}


Table 4: The use of each metadiscourse element in Persian corpus

\begin{tabular}{|c|c|c|c|c|c|c|c|c|c|c|c|c|c|}
\cline { 3 - 14 } \multicolumn{1}{c|}{} & \multicolumn{10}{c|}{ Metadiscourse } \\
\hline Persian & $\begin{array}{c}\text { No. of } \\
\text { words }\end{array}$ & T\% & Fm\% & En\% & Ev\% & Co\% & Total\% & H\% & Bo\% & Am\% & Eng\% & Sm\% & Total\% \\
\hline $\begin{array}{c}\text { Computer } \\
\text { engineering }\end{array}$ & 26181 & 1.54 & 0.80 & 0.73 & 0.33 & 1.42 & $\mathbf{4 . 8 2}$ & 0.25 & 0.40 & 0.09 & 0.01 & 0.32 & $\mathbf{1 . 0 7}$ \\
\hline $\begin{array}{c}\text { Applied } \\
\text { linguistics }\end{array}$ & 25510 & 1.70 & 0.95 & 0.35 & 0.90 & 1.33 & $\mathbf{5 . 2 3}$ & 0.29 & 0.86 & 0.18 & 0.04 & 0.35 & $\mathbf{1 . 7 2}$ \\
\hline Total & 51691 & 3.24 & 1.75 & 1.08 & 1.23 & 2.75 & $\mathbf{1 0 . 0 5}$ & 0.54 & 1.2 & 0.27 & 0.05 & 0.67 & $\mathbf{2 . 7 9}$ \\
\hline z-test result & $* * * * *$ & 1.44 & 1.83 & $2.74^{*}$ & $8.31^{*}$ & 0.87 & $\mathbf{2 . 1 3 3}$ & $2.8^{*}$ & $21.57^{*}$ & $2.79^{*}$ & $2.16^{*}$ & 0.59 & $\mathbf{6 . 3 0 9 *}$ \\
\hline
\end{tabular}

Table 5: The use of metadiscourse elements in Computer engineering across the two languages

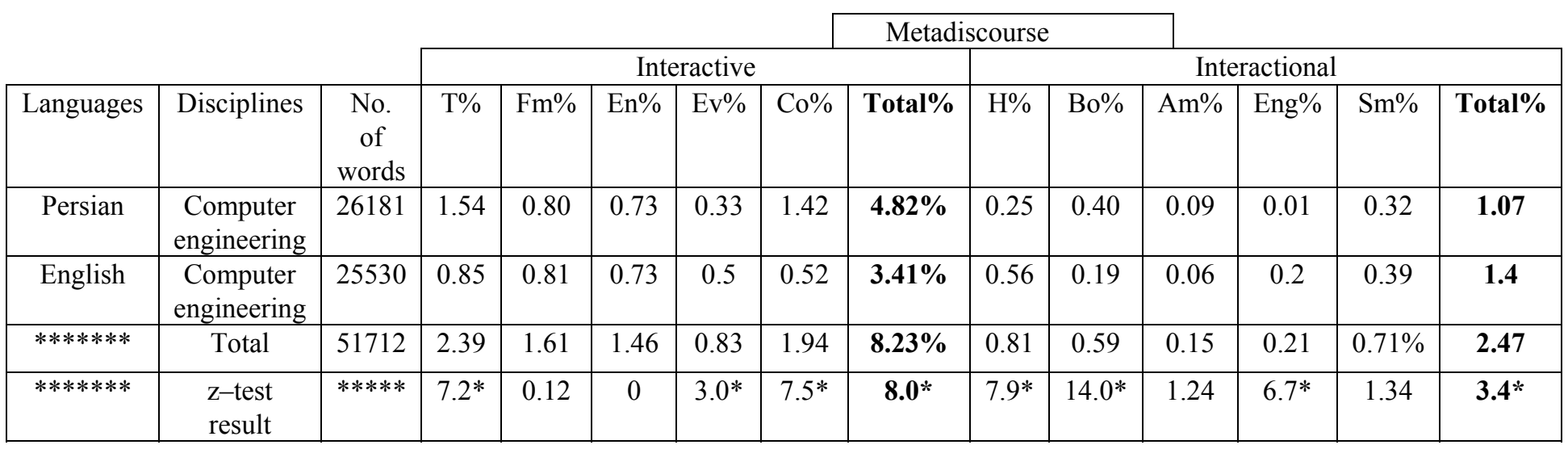

Critical level: 1.96

$\mathrm{P}<.05$

* Significant

Table 6: The use of metadiscourse elements in Applied Linguistics across the two languages

\begin{tabular}{|c|c|c|c|c|c|c|c|c|c|c|c|c|c|c|}
\hline & \multicolumn{12}{|c|}{ Metadiscourse } \\
\hline & & & \multicolumn{6}{|c|}{ Interactive } & \multicolumn{6}{|c|}{ Interactional } \\
\hline $\begin{array}{c}\text { Languag } \\
\text { es }\end{array}$ & Disciplines & $\begin{array}{l}\text { No. of } \\
\text { words }\end{array}$ & $\mathrm{T} \%$ & Fm\% & En\% & Ev\% & $\begin{array}{l}\mathrm{Co} \\
\%\end{array}$ & $\begin{array}{c}\text { Total } \\
\% \\
\end{array}$ & $\mathrm{H} \%$ & $\begin{array}{c}\text { Bo } \\
\%\end{array}$ & $\begin{array}{c}\mathrm{Am} \\
\%\end{array}$ & Eng\% & $\mathrm{Sm} \%$ & $\begin{array}{c}\text { Tota } \\
\% \\
\end{array}$ \\
\hline Persian & $\begin{array}{c}\text { Applied } \\
\text { linguistics }\end{array}$ & 25510 & 1.70 & 0.95 & 0.35 & 0.90 & 1.33 & 5.23 & 0.29 & 0.86 & 0.18 & 0.04 & 0.35 & 1.72 \\
\hline English & $\begin{array}{c}\text { Applied } \\
\text { linguistics }\end{array}$ & 25071 & 1.25 & 0.49 & 0.38 & 1.21 & 1 & 4.33 & 0.96 & 0.42 & 0.08 & 0.13 & 0.62 & 2.21 \\
\hline$* * * * * *$ & Total & 50581 & 2.95 & 1.44 & 0.73 & 2.11 & 2.33 & 9.56 & 1.25 & 1.28 & 0.26 & 0.17 & 0.97 & 3.93 \\
\hline$* * * * * *$ & $\begin{array}{l}\text { z-test } \\
\text { results }\end{array}$ & $* * * * *$ & $4.1^{*}$ & $6.1^{*}$ & 0.5 & $3.4^{*}$ & $3.4^{*}$ & 4.7* & $\begin{array}{c}31.1 \\
*\end{array}$ & $\begin{array}{c}20.1 \\
*\end{array}$ & $3.1^{*}$ & $3.4^{*}$ & $4.3^{*}$ & 3.9* \\
\hline
\end{tabular}

